\title{
Influence of socioeconomic and health care development on infant and perinatal mortality in Spain 1975-86
}

Pablo Lardellli, José Ignacio Blanco, Miguel Delgado-Rodríguez, Aurora Bueno, Juan de Dios Luna, Ramón Gálvez

\begin{abstract}
Study objective-This study aimed to analyse the influence of social, economic, and health development on infant and perinatal mortality in Spain between 1975 and 1986, and to identify possible changes in these relationships over time.

Design-Study of the association between mortality and a range of variables.

Setting-50 Spanish provinces.

Measurements and main results-Mean infant and perinatal mortality were estimated for two periods-1975-8 and 1983-6. Social, economic, and health care indicators were collected as independent variables for these two periods. The rates of variation between periods were estimated for each variable. Multiple linear regression models were used to define the association between infant and perinatal mortality and their respective rate of variation with the former indicators. Mean familial income was the main predictive factor for infant and perinatal mortality in the first period but in the second period health care indicators were more relevant.

Conclusions-The reduction in Spanish infant and perinatal mortality over the period can be attributed mainly to the improvement in prenatal and neonatal health care in Spain in recent years, while economic factors seem less important.
\end{abstract}

J Epidemiol Community Health 1993; 47: 260-264

Infant and perinatal mortality in Spain have fallen steeply in the past two decades and are now the same as in most developed countries. ${ }^{12}$ Infant mortality has fallen from 18.9 in 1975 to 9.2 in 1986 , a decrease of $51 \cdot 3 \%{ }^{3}$ This trend has been similar for perinatal mortality, which showed a $50.7 \%$ reduction between $1975(21 \cdot 1)$ and 1986

Department of Preventive Medicine and Public Health, Faculty of Medicine, University of Granada, Avda de Madrid no 11, 18012 Granada, Spain P Lardelli

J I Blanco

M Delgado-Rodríguez

A Bueno

R Gálvez

Department of

Biostatistics,

University of Granada,

Spain

J de Dios Luna

Correspondence to:

Dr P Lardelli

Accepted for publication November 1992 $(10 \cdot 7){ }^{3}$ These reductions in mortality are similar to, or even higher than, those seen in other European countries. ${ }^{4-6}$

The reductions in infant and perinatal mortality can be partly explained by the socieconomic and health care development maintained by Spain, especially since the second half of the 1970 s (just as they have been explained in other countries).$^{7-9}$ Neither the starting level nor the speed of this development has been the same in all the Spanish regions, however, which may explain the wide inter-regional differences that still remain. ${ }^{10-12}$ This situation also occurs in other European countries. ${ }^{9} 1314$

This study aimed to assess the influence of socioeconomic and health developments on infant and perinatal mortality in Spain between 1975 and 1986 and tried to identify changes in the pattern over time.

\section{Methods}

Two periods have been considered $-1975-8$ and 1983-6. For each year of both periods, and for the 50 Spanish provinces, the following dependent and independent variables were collected:

\section{DEPENDENT VARIABLES}

Using data from the General Register of Spanish Population, ${ }^{15}$ the infant mortality (total number of infant deaths (less than 1 year old) per 1000 live births) and perinatal mortality (total number of perinatal deaths (late fetal deaths plus early neonatal deaths) per 1000 births) were calculated.

\section{INDEPENDENT VARIABLES}

Using data from the General Register of Spanish Population $^{15}$ and the Spanish Population Statistics Annual, ${ }^{16}$ the following sociodemographic variables were obtained:

Proportion of young population (less than 24 years old);

Birth rate (total births per 1000 inhabitants);

Density of population;

Inter-regional migration rate (total number of emigrants to other provinces per 1000 inhabitants);

Proportion of illegitimate births;

Proportion of dystocic deliveries.

From the Economic Report of the Bilbao Bank ${ }^{17}$ the following socioeconomic indicators were obtained, generally every two years:

Familial mean income;

Gross domestic product (GDP)/1000 inhabitants;

Proportion of active population;

Unemployment rate.

Mean familial income and GDP were adjusted for each year according to the respective consumer price indices.

The following health care indicators were obtained using data from the General Register of Spanish Population, ${ }^{15}$ Spanish Population Statistics Annual, ${ }^{16}$ and the Spanish Hospital General Statistics: ${ }^{18}$

Proportion of live births not attended by health care workers;

Total number of midwives/1000 live births; Hospital beds/ 1000 inhabitants; old);

Obstetric-gynaecologic beds/1000 women;

Incubators/1000 live births;
Paediatric beds/ 1000 children (from 0 to 14 years 
Health care workers/1000 inhabitants, divided into:

Physicians/1000 inhabitants;

Paediatricians/ 1000 children;

Obstetricians and gynaecologists/1000

women;

Nurses/1000 inhabitants.

From these annual data mean values for all the variables for each province were estimated for the two study periods. National values were also calculated. All the mean values were weighted by the size of the denominators of each variable.

The mean value for each variable for the two periods were used to calculate the percentage of change in the second period with regard to the first (which was taken as the reference).

Firstly, a multiple linear regression model ${ }^{19}$ was used to analyse the relationship between the provincial infant and perinatal mortality rates and the independent variables for each time period.

Successive multiple linear regression models were applied to assess the change in these relationships over time using two different approaches. In the first, infant and perinatal mortality for the second period (IMR2 and PMR2, respectively) were used as dependent variables. In the second, their respective percentages of change between periods ( $P I M R$ and pPMR, respectively) were considered as dependent variables. For both approaches, the values of all the variables in the first period (including infant and perinatal mortality rates, IMR1 and PMR1 respectively) and their respective percentage of change between periods were considered as the independent factors.

Four multiple regression analyses were applied for each rate. It should be pointed out that there was no a priori priority order established in the independent factors. Thus, the initial criterion for selecting the best model was to take into account the one with the best predictive power with a significance level of $0 \cdot 15$. This predictive power was evaluated in respect of two parameters - the adjusted determination coefficient of the model and the Mallow's Cp coefficient. All the models were obtained by using the Furnival-Wilson algorithm, ${ }^{20}$ which, by computing only a small fraction of all the possible regression models, enabled us to identify the best subgroup of independent variables. For practical and operative reasons, a maximum number of five independent terms was initially specified. In a second phase, a stepwise multiple regression analysis ${ }^{19}$ was subsequently applied in an attempt to increase the power of the preceding model by the addition of new independent terms.

Statstical analysis was performed using the BMDP statistical package, implementing the $2 \mathrm{R}$ and $9 \mathrm{R}$ programs. ${ }^{20}$

\section{Results}

INFANT MORTALITY RATE

The model obtained for IMR1 (table 1) includes four variables: familial mean income, birth rate, proportion of live births not attended by health workers, and the number of health care workers/ 1000 inhabitants. The partial correlation coefficient is negative for the first two factors and positive for the other two. The adjusted determination coefficient fo the model was 0.53 .

In the second period, the predictive model for IMR2 is composed of the following factors, in order of inclusion: the proportion of live births not attendant by health workers, paediatric beds $/ 1000$ children; and incubators/ 1000 live births, with an adjusted determination coefficient of 0.31 .

In the third model, IMR2 was considered as the dependent variable. The values of all the factors in the first period were taken as independent factors as were their respective rates of variation between periods. The following variables were included in the model: IMR1, the percentage of change in the proportion of dystocic deliveries; the number of midwives/1000 live births; the proportion of live births not attended by health workers; and the percentage of change in the number of nurses/ 1000 inhabitants. The last variable was the only one which held a negative partial correlation coefficient. The adjusted determination coefficient of the model could explain $44 \%$ of the interprovincial variability in IMR2.

Finally, taking the pIMR as the dependent term, and considering the same independent factors as
Table I Multiple regression analysis for infant mortality rates (IMR)

\begin{tabular}{|c|c|c|c|c|c|c|}
\hline Variables & $\begin{array}{l}(1) \\
I M R\end{array}$ & $\begin{array}{l}(2) \\
I M R 2\end{array}$ & $\begin{array}{l}(3) \\
I M R\end{array}$ & & & $\begin{array}{l}\text { (4) } \\
\text { pIMR }\end{array}$ \\
\hline $\begin{array}{l}\text { IMR1 } \\
\text { Familial mean income } \\
\text { Birth rate } \\
\text { Health care workers } / 1000 \text { inhabitants } \\
\text { Midwives } 1000 \text { live births } \\
\% \text { live births not attended by health worker } \\
\text { Paediatric beds } / 1000 \text { children } \\
\text { Incubators } 1000 \text { live births }\end{array}$ & 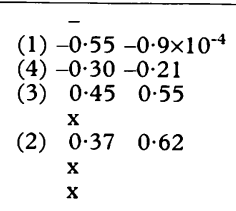 & 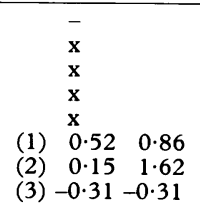 & $\begin{array}{l}\text { (1) } \\
\text { (4) } \\
(5)\end{array}$ & $\begin{array}{l}0 \cdot 45 \\
\mathbf{x} \\
\mathbf{x} \\
\mathbf{x} \\
0 \cdot 23 \\
0 \cdot 33 \\
\mathbf{x} \\
\mathrm{x}\end{array}$ & $\begin{array}{l}0 \cdot 21 \\
0 \cdot 30\end{array}$ & $\begin{array}{l}\text { (2) }-0 \cdot 45-1 \cdot 13 \\
\mathrm{x} \\
\mathrm{x} \\
\mathrm{x} \\
\mathrm{x} \\
\mathrm{x} \\
\mathrm{x} \\
\mathrm{x}\end{array}$ \\
\hline $\begin{array}{l}\% \text { change in nurses } / 1000 \text { inhabitants } \\
\% \text { change in the proportion of dystocic }\end{array}$ & - & - & (2) - & -0.45 & -0.02 & (1) $-0.44-0.13$ \\
\hline $\begin{array}{l}\text { deliveries } \\
\% \text { change in the no of midwives } / 1000 \text { live } \\
\text { births } \\
\% \text { change in the proportion of active } \\
\text { population }\end{array}$ & - & - & (3) & $0 \cdot 24$ & 0.002 & (3) $-0.30-0.01$ \\
\hline $\begin{array}{l}\text { population } \\
\text { Mallow's coefficient } \\
\text { Determination coefficient } \\
\end{array}$ & $\begin{array}{c}- \\
-2 \cdot 42(5 \text { var }) \\
0.53\end{array}$ & $\begin{array}{r}-1 \cdot 07 \text { ( } 3 \text { var) } \\
0 \cdot 31\end{array}$ & & $\begin{array}{l}x \\
54 \\
14\end{array}$ & & $\begin{array}{l}(4)-0 \cdot 25-0 \cdot 30 \\
-9 \cdot 70(5 \text { var }) \\
0 \cdot 44\end{array}$ \\
\hline \multicolumn{7}{|c|}{$\begin{array}{l}(1)=\text { model for IMR in the first period }(1975-8) \text {. The figures for the variables in the first period were used for the analysis. } \\
(2)=\text { model for IMR in the second period }(1983-6) \text {. The figures for the variables in the second period were used for the } \\
\text { analysis. } \\
\text { (3)=model for IMR in the second period }(1983-6) \text {. The figures for the variables in the first period and their respective } \\
\text { percentages of change between periods were used for the analysis. } \\
\text { (4)=model for percentage of change of IMR. The figures for the variables in the first period and their respective percentages of } \\
\text { change between periods were used for the analysis. } \\
\text { For each variable, the step in which it was entered in the model is indicated in parentheses. The second figure is the partial } \\
\text { correlation coefficient, and, on the right, the regression coefficient (beta) is represented. } \\
\text { =variable not used in the analysis; } x=\text { variable not included in the final model. }\end{array}$} \\
\hline
\end{tabular}


in the previous model, three variables remain in this new model: IMR1, inversely associated with pIMR; the percentage of change in the number of nurses/1000 inhabitants; and the percentage of change in the proportion of dystocic deliveries. These two last variables maintain the same partial correlation coefficient as in the previous model. The model also included the percentage of change in midwives/ 1000 live births and the percentage of change in the proportion of active population; both factors inversely associated with pIMR. The adjusted determintion coefficient of the model was 0.44 .

PERINATAL MORTALITY RATE

The model obtained for PMR1 (table II) contained three independent terms: familial mean income, obstetric and gynaecologic beds $/ 1000$ women, and the density of population; all of them inversely associated with PMR1. The adjusted determination coefficient of the model was 0.49 .

The model for PMR2 was composed of the following terms: the proportion of live births not attended by health workers, birth rate, paediatric beds/1000 children, total hospital beds/1000 inhabitants, and obstetricians and gynaecologists/ 1000 women. These two last factors were inversely related with PMR2, while the other held a positive partial correlation coefficient. The value of the adjusted determination coefficient was 0.35 .

In the third model (taking the values of the variables in the first peroid, as well as their respective rate of variation as the independent terms of the equation), the model for IMR2 included the following variables: physicians $/ 1000$ inhabitants, percentage of change in the number of midwives $/ 1000$ live births, percentage of change in the number of nurses/ 1000 inhabitants, PMR1, and paediatric beds $/ 1000$ children. The partial correlation coefficient had a positive value for the last two factors and was negative for the others. The adjusted determination coefficient reached a value of $0 \cdot 48$.

Finally, the model for pPMR initially introduced five variables, four of which occurred in the previous one: physicians/1000 inhabitants, percentage of change in the number of midwives/ 1000 live births, PMR1, and paediatric beds $/ 1000$ children. These variables held the same kind of association with pPMR as in the previous model, with the exception of PMR1, which changed the sign of its partial correlation coefficient. The fifth variable introduced was the percentage of change in the rate of illegitimate births, which had a negative partial correlation coefficient. This was the only model in which the stepwise regression added a new independent term: the percentage of change in the number of physicians $/ 1000$ inhabitants, also with a negative partial correlation coefficient. The model was able to explain $46 \%$ of the interprovincial variation in $\mathrm{pPMR}$.

\section{Discussion}

The association between infant and perinatal mortality and social, economic, and health related variables has been widely reported in aggregate studies $^{21-24}$ and person based designs. ${ }^{25-27}$ In Spain, although several reports have been published, ${ }^{101128}$ the temporal evolution of these associations has not been assessed until now.

In the present report, the strongest determinant of both infant and perinatal mortality for the period 1975-8 was the mean family income. This was a better predictor than the health service provision indicators. These results agree with those reported by Salleras $e t a l^{28}$ and Zurriaga $e t$ $a l^{10}$ both of whom analysed a similar period. In the United Kingdom, significant associations between several socioeconomic indicators and regional infant $^{29}$ and perinatal mortality rates ${ }^{22} 30$ have also been found. The relationship between economic variables and perinatal mortality received strong support in a WHO sponsored comparative study across eight countries. ${ }^{31}$

In the models for 1983-6, however, the economic component was replaced by health care indicators that were inversely related to mortality rates. Buck and Bull ${ }^{32}$ showed that health care indicators were stronger predictors than economic factors for infant mortality in the most developed countries. According to our results, they became so in Spain in the 1980s, which suggests a time lag in achieving the level of other developed countries.

On the other hand, the variance explained by the models for the period 1983-6 is clearly lower
Table II Multiple regression analysis for perinatal mortality rates (PMR)

\begin{tabular}{|c|c|c|c|c|}
\hline Variables & $\begin{array}{l}\text { (1) } \\
P M R 1\end{array}$ & $\begin{array}{l}\text { (2) } \\
P M R 2\end{array}$ & $\begin{array}{l}(3) \\
P M R 2\end{array}$ & $\begin{array}{l}\text { (4) } \\
p P M R\end{array}$ \\
\hline PMR1 & - & - & (2) $0.33 \quad 0.43$ & (5) $-0.32-0.75$ \\
\hline Density of population & (3) $-0.30-0.01$ & $\mathbf{x}$ & $\mathbf{x}$ & $\mathbf{x}$ \\
\hline Birth rate & $\mathrm{x}$ & (3) $0.24 \quad 0.40$ & $\mathbf{x}$ & $\mathbf{x}$ \\
\hline Familial mean income & (1) $-0.64-0.6 \times 10^{-4}$ & $\mathrm{x}$ & $\mathbf{x}$ & $\mathrm{x}$ \\
\hline Hospital beds/ 1000 inhabitants & $\mathbf{x}$ & (2) $-0.33-0.52$ & $\mathrm{x}$ & $\mathbf{x}$ \\
\hline Paediatric beds $/ 1000$ children & $\mathbf{x}$ & (5) $0.25 \quad 1.57$ & (3) 0.34 & (3) $0.44 \quad 14 \cdot 1$ \\
\hline Obstetric beds/ 1000 women & (2) $-0.32-4 \cdot 25$ & $\mathbf{x}$ & $x$ & $x$ \\
\hline Physicians $/ 1000$ inhabitants & $\mathbf{x}$ & $x$ & (1) $-0.46-3 \cdot 14$ & (2) $-0.23-20 \cdot 9$ \\
\hline Obstetrician-gynaecologist $/ 1000$ women & $\mathbf{x}$ & (4) $-0 \cdot 20-1 \cdot 38$ & $\mathbf{x}$ & $\mathbf{x}$ \\
\hline$\%$ live births not attended by health worker & $\mathbf{x}$ & (1) $0.47 \quad 0.77$ & $\mathbf{x}$ & $\mathrm{x}$ \\
\hline $\begin{array}{l}\% \text { change in midwives } / 1000 \text { live births } \\
\% \text { change in nurses } / 1000 \text { inhabitants } \\
\% \text { change in the } \% \text { of illegitimate live births } \\
\% \text { change in physicians } / 1000 \text { inhabitants }\end{array}$ & $\begin{array}{l}- \\
- \\
- \\
-\end{array}$ & $\begin{array}{l}- \\
- \\
- \\
-\end{array}$ & $\begin{array}{l}\text { (4) }-0.36-0.0004 \\
(5)-0.37-0.03 \\
\mathbf{x} \\
\mathbf{x}\end{array}$ & $\begin{array}{l}\text { (1) }-0.35-0.02 \\
x \\
\text { (4) }-0.30-0.04 \\
(6)-0.36-0.14\end{array}$ \\
\hline $\begin{array}{l}\text { Mallow's coefficient } \\
\text { Determination coefficient }\end{array}$ & $\begin{array}{c}-3 \cdot 66 \text { ( } 3 \text { var) } \\
0.49\end{array}$ & $\begin{array}{l}-2 \cdot 82 \\
0.35\end{array}$ & $\begin{array}{l}-8.03 \text { (5 var) } \\
0.48\end{array}$ & -2.60 ( 5 var) \\
\hline
\end{tabular}

(1)=model for PMR in the first period (1975-8). The figures for the variables in the first period were used for the analysis. (2)=model for PMR in the second period $(1983-6)$. The figures for the variables in the second period were used for the analysis.

(3)=model for PMR in the second period (1983-6). The figures for the variables in the first period and their respective percentages of change between periods were used for the analysis.

(4)=model for percentage of change PMR. The figures of the variables in the first period and their respective percentages of change between periods were used for the analysis.

For each variable, the step in which it was entered in the model is indicated in parentheses. The second figure is partial correlation coefficient, and, on the right, the regression coefficient (beta) is represented.

$=$ variable not used in the analysis; $x=$ variable not included in the final model. 
than that of the models for $1975-8$. This decrease is greater for infant mortality (from 0.53 to 0.31 ) than for perinatal mortality (from 0.49 to 0.35 ), which agrees with the increasing value that perinatal mortality is receiving as a health indicator in developed countries. ${ }^{33}$ This does not, however, obviate the fact that there is a decreasing association between socioeconomic and health service provision indicators, and both rates. This trend, typical of developed countries, ${ }^{34}$ can be explained by the decreasing rates over time, which reduce absolute interprovincial variability. When a certain level of development is reached, the association between the rates studied and this development lessens. This occurs when rates achieve "difficult to improve on" values. It is easy to verify that Spain reached the mortality figures of its neighbouring developed European countries during the 1980 s. $^{12}$

With regard to the models of time trends, several facts should be noted. Firstly, the figures for both rates for the second period (1983-6) are dependent on those of the first 1975-8. This means that the provinces with the best and the worst values are the same for both periods studied-that is, the geographical differences remain. ${ }^{10-12}$ On the other hand, there is an inverse association between the percentage of change (between the two periods considered) and the initial figures. This means that the provinces with the highest figures experience the greatest reductions, and vice versa. This result does not support the finding by Garcia-Gil et al. ${ }^{12}$ These authors do not find an association between initial perinatal mortality figures and percentages of decrease for the period 1975-83. This discrepancy may be explained by the different unit of study (autonomous regions instead of provinces). Unfortunately, our results do not suggest that extreme provincial figures get closer with time. As mentioned above, when mortality rates decrease with time the same happens with the variance of data. Therefore, if the average rate figures are standardised, using their standard deviations for each year, an increased dispersion of the provincial figures as reference to the mean national figure for the last years is appreciated. ${ }^{35}$

Analysis of the variables that best explain the evolution of both rates during the periods studied shows that the changes in these rates are strongly related to improvements in health care indicators (increase in the number of midwives or nurses, etc) and not to amelioration in other indicators. According to the model of Pendleton and Yang, ${ }^{36}$ improvement in basic health care is most beneficial when a country is at an early development stage. Rosero-Bixby ${ }^{37}$ in Costa Rica, and Sandiford $e a^{38}$ in Nicaragua offer a similar explanation for the decrease in infant mortality in recent years. However, Pendleton and Yang also suggest that when a certain level is reached, economic factors become far more important. Thus, in Cuba (the country with the best infant mortality in central and South America) socioeconomic variables are the most important determinants. ${ }^{39}$ Furthermore, bearing in mind our results and those of others, ${ }^{40-42}$ it seems that in the most highly developed countries, reductions in infant and postnatal mortality are related more closely to improvements in specialised health care than to socioeconomic factors. ${ }^{943}$ Therefore, three stages in the evolution of infant and perinatal mortality can be highlighted in every country: (a) an initial relationship with improvements in basic health care which progresses to (b) an association with economic factors; and (c) a return to a dependence upon specialised prenatal and neonatal health care. Our results may mark the boundaries of (b) and (c) in Spain.

It would have been desirable to consider not only health care indicators but also health service use indicators. Although a direct relationship between these could be assumed, it is obvious that health service use reflects a wider dimension of the association between health care and improvement in mortality rates, which could not be measured in our study. Unfortunately, there are few reliable sources of data on the rates of use of health care facilities in Spain, and they are not available for all the Spanish provinces or for all the years studied.

The decreasing importance of economic indicators on mortality over time can be explained, at least partly, by a decreasing reliance of health care on economic development. This has been noticed in highly developed countries, such as Sweden, ${ }^{43}$ and is partly revealed in our results where a decrease in the correlation coefficients of familial income with other indicators was observed between 1975-8 and 1983-6 (table III). Another thing should be remembered-the differences within a country get smaller as the level of development improves, and this hinders the finding of significant associations with other variables.

Table III Simple correlation coefficients between familial mean income and several health care indicators in both periods: $1975-8$ and 1983-6.

\begin{tabular}{lcc}
\hline & \multicolumn{2}{c}{ Familial mean income } \\
\cline { 2 - 3 } Variables & $1975-8$ & $1983-6$ \\
\hline Obstetric-gynaecologic & & \\
beds/1000 women & 0.43 & 0.12 \\
Physicians/1000 inhabitants & 0.46 & 0.20 \\
Paediatric beds/1000 children & 0.34 & 0.04 \\
\% live births not attended by health & & \\
$\quad$ worker & -0.35 & -0.38 \\
Incubators/1000 live births & 0.32 & 0.28 \\
Nurses/1000 inhabitants & 0.03 & 0.02 \\
Midwives/1000 live births & 0.38 & 0.25
\end{tabular}

Finally, it should be emphasised that several factors maintain an inverse relationship, as opposed to that which would be expected. For instance, the number of paediatrics beds per thousand population is positively related to postnatal mortality. This may reflect an error in registering death - to the place of death instead to the place of residence. The provinces with the highest number of paediatric beds (the more developed) look after patients from neighbouring provinces.

In conclusion, for Spain as for other developed countries the decreases in infant and postnatal mortality observed for recent years are attributable to improvements in health care. Starting in the 1980 s, when mortality rates had reduced considerably, determinants have shifted from economic factors to health care indicators, especially with regard to infant mortality.

We thank David Peiris for helping us to translate this manuscript into English. 
1 Información sanitaria y epidemiologia. Indicadores de salud. Madrid: Ministerio de Sanidad y Consumo, 1990

2 Organization for Economic Co-operation and Development. Health care systems in transition. Paris: OECD, 1990. OECD Social Policy Studies no 7.

3 Ministerio de Sanidad y Consumo. Mortalidad infantil en España. Boletín epidemiológico semanal 1990: Madrid: Ministerio de Sanidad y Consumo, 1990 Semanas 49-50, no 1875.

4 Piekkala P, Erkkola R, Kero P, Tenuovo A, Sillanpaa $M$. Declining perinatal mortality in a region of Finland, 19681982. Am ₹ Public Health 1985; 75: 156-60.

5 Kunitz SJ, Simic S, Odoroff CH. Infant mortality and economic instability in Yugoslavia. Soc Sci Med 1987; 11: 953-60.

6 Matsagnis $M$. High infant mortality in the big cities of Greece. F Epidemiol Community Health 1991; 45: 171-2.

Dujardin S, Vandenbussche P, Buekers P, Wollast E. Evolution recenté de la mortalité infantile. Le cas de la Belgique. Arch Fr Pediatr 1986; 43: 275-8.

8 Bloom B. Changing infant mortality: the need to spend more while getting less. Pediatrics 1984; 73: 862-66.

9 Hansen-Koenig D, Manciaux M, Deschamps JP. La mortalité péri-natale au Grand Duché de Luxembourg. Evolution de 1969 à 1979. Rev Epidem Santé Publique 1983; 31: 129-42.

10 Zurriaga O, Alfonso JL, Sanchis B, Prado MJ, Cortina P. Factores determinantes de la mortalidad infantil en España. Salud Publica Mex 1990; 32: 665-72.

11 Lardelli P, Masa J, Maderuelo M, Delgado M, Galvez R. Infant, neonatal, postneonatal and perinatal mortality rates. Interannual and interregional differences. Soc Sci Med 1990; 33: $613-20$.

12 Garcia-Gil C, Cortés M, Durán C. Mortalidad perinatal en España. La necesidad del enfoque epidemiológico. Rev en España. La necesidad del enfoque epide

13 Paccaud F. Epidemiologie de la mortalité périnatale: progrès et disparités dans les pays développés. Médecine et Hygiène 1987; 48: 2928-34.

14 Parazzini F, La Vecchia C. Perinatal and infant mortality in various geographic areas of Italy. Am $\mathcal{\jmath}$ Public Health 1991; 81: 933.

15 Instituto Nacional de Estadistica. Movimiento natural de la población. Madrid: Instituto National de Estadística, Various years.

16 Instituto Nacional de Estadística. Anuario de la Población Española. Madrid: Instituto Nacional de Estadística, Various years.

17 Banco de Bilbao. Informes económicos del Banco de Bilbao. Madrid: Banco de Bilbao, Various years.

18 Instituto Nacional de Estadistica. Estadistica de establecimientos sanitarios. Madrid: Instituto Nacional de establecimientos sanitarios. Madrid: Instituto Nacional de
Estadistica, 1975-84.

19 Snedecor GW, Cochran

Snedecor GW, Cochran WR. Statistical methods. 7th ed. Iowa: The Iowa State University Press, 1980.

20 Dixon WJ. BMDP Statistical Software. Los Angeles: University of California Press, 1985 reprinting, 198

21 Woolhandler S, Himmelstein DU. Militarism and mortality. Lancet 1985; i: 1375-8.

22 West RR. Perinatal and infant mortality in Wales: interdistrict variations and associations with socioenvironmental characteristics. Int $\mathcal{f}$ Epidem 1988; 17: 392-6.

23 Stembera Z. Country wide analysis of perinatal outcome. $\mathcal{F}$ Perinat Med 1988; 16: 391-6.
24 Stockwell EG, Swanson DA, Wicks JW. Economic status differences in infant mortality by cause of death. Public Health Rep 1988; 103: 135-42.

25 Nersesian WS. Infant mortality in socially vulnerable populations. Annu Rev Public Health 1988; 9: 361-77.

26 Paneth N, Wallenstein S, Kiely JL, Susser M. Social class indicators and mortality in low birth weight infants. $A m \mathcal{J}$ Epidemiol 1982; 116: 364-75.

27 Gould JB, Davey B, Leroy S. Socioeconomic differentials and neonatal mortality: racial comparison of California and neonatal mortality: racial comparis

28 Salleras L, Sentis J, Canela J, Garcia A. Facteurs sociaux et d'assistence sanitaire et mortalité perinatale en Espagne. Étude écologique. Rev Epidem Santé Publ 1988; 36: 30-5.

29 Bradshaw J, Edwards $H$, Lawton $D$, et al. Area variations in infant mortality. F Epidemiol Community Health 1982; 32 11-16.

30 Knox EG, Marshall T, Kane S, Green A, Mallet R. Social and health care determinants of area variations in perinatal mortality. Community Medicine 1980; 2: 282-90.

31 World Health Organisation. $A$ WHO report on social and biological effects on perinatal mortality. Vol I and II. Budapest, Hungary: Statistical Publishing House, 1978. Report on an Hungary: Statistical Publishing Hous

32 Buck C, Bull S. Preventable causes of death versus infant mortality as an indicator of the quality of health service. Int $\mathcal{F}$
Health Serv $1986 ; 16: 553-63$.

33 Piedrola G, Dominguez M, Cortina P, et al: Medicina preventiva y salud pública. 9th ed. Barcelona: MassonSalvat, 1991

34 Bolúmar F, Garrucho G, Megia MJ et al. La mortalidad infantil en España. I: la mortalidad infantil en España 1900-1976. Rev Sanid Hig Publica 1981; 55: 1205-19.

35 Lardelli P, Luna JD, Masa J, López R, Delgado-Rodriguez $M$, Gálvez $R$. Desequilibrios en salud. La mortalidad perinatal e infantil en España. Gaceta Sanitaria 1993; 7 : 21-6.

36 Pendleton B, Yang SW. Socioeconomic and health effects on mortality declines in developing countries. Soc Sci Med 1985; 5: 453-60.

37 Rosero L. Costa Rica saves infant lives. World Health Stat $Q$ 1989; 9: 439-43.

38 Sandiford P, Morales P, Gorter A, Coyle E, Smith GD. Why do child mortality rates fall? An analysis of the Nicaraguan experience. Am $\mathcal{F}$ Public Health 1991; 81: 30-7.

39 González G, Herrera L. Desarrollo social y mortalidad infantil, 1977-1986. Cuba. Un análisis regional. Rev Saude Publica 1990; 24: 186-95.

40 Tenuovo A, Kero P, Piekkala P, Sillanpaa M, Erkkola R. Advances in perinatal care and declining regional neonatal mortality in Finland, 1968-82. Acta Pediatr Scand 1986; 75: 362-9.

41 Williams RL, Chen PM. Identifying the sources of the recent decline in perinatal mortality rates in California. $N$ Engl $\mathcal{F}$ Med 1982; 306: 207-14.

42 David RJ, Siegal E. Decline in neonatal mortality 1968 to 1977: better babies or better care? Pediatrics 1983; 71 : $531-40$.

43 Ericson A, Eriksson M, Kallen B, Zetterstrom R. Socioeconomic variables and pregnancy outcome. 2. Infan and child survival. Acta Paediatr Scand 1990; 79: 1009-16.

44 Ericson A, Eriksson M, Westerholm P, Zetterstrom R. Pregnancy outcome and social indicators in Sweden. Acto Paediatr Scand 1984; 73: 69-74. 